\title{
Vacuum ultraviolet photochemistry of solid acetylene: a multispectral approach
}

\author{
Steven H. Cuylle ${ }^{1}$, Dongfeng Zhao ${ }^{1}$, Giovanni Strazzulla ${ }^{2}$, and Harold Linnartz ${ }^{1}$ \\ ${ }^{1}$ Sackler Laboratory for Astrophysics, Leiden Observatory, Leiden Universtiy, PO Box 9513, 2300 RA Leiden, The Netherlands \\ e-mail: Linnartz@strw.leidenuniv.nl \\ ${ }^{2}$ INAF - Osservatorio Astrofisico di Catania, via S. Sofia 78, 95123 Catania, Italy
}

Received 11 June 2014 / Accepted 26 July 2014

\begin{abstract}
Aims. Gas phase acetylene $\left(\mathrm{C}_{2} \mathrm{H}_{2}\right)$ and polyynes $\left(\mathrm{H}(-\mathrm{C} \equiv \mathrm{C}-)_{m} \mathrm{H}\right)$ are ubiquitous in the interstellar medium. However, astrochemical models systematically underestimate the observed abundances, supporting the idea that enrichment from the solid state takes place. In this laboratory-based study, we investigate the role $\mathrm{C}_{2} \mathrm{H}_{2}$ plays in interstellar ice chemistry and we discuss the way its photoproducts may affect gas phase compositions.

Methods. $\mathrm{C}_{2} \mathrm{H}_{2}$ ice is investigated under vacuum ultraviolet (VUV) irradiation in its pure form as present in the atmosphere of Titan and in a water-dominated ice as present on grain mantles in molecular clouds and on comets. To disentangle the photochemical network, a unique, complementary combination of infrared and ultraviolet-visible (UV-VIS) spectroscopy is used.

Results. From the experimental results, it can be concluded that the VUV-induced solid state $\mathrm{C}_{2} \mathrm{H}_{2}$ reaction network is dominated by polymerization resulting in the formation of polyynes at least up to $\mathrm{C}_{20} \mathrm{H}_{2}$ and larger polyyne-like molecules. At low temperatures, this process takes place very efficiently and suggests low barriers. When extending this reaction scheme to a water-rich environment, the dominant reaction products are $\mathrm{CO}$ and $\mathrm{CO}_{2}$ but the simultaneous detection of polyyne like molecules is evidence that the reactions as observed in pure $\mathrm{C}_{2} \mathrm{H}_{2}$ ice persist.

Conclusions. From the spectroscopic evidence as presented in this laboratory study, it is concluded that the formation of polyynes upon VUV irradiation of interstellar ices is a process that may contribute to at least part of the observed gas phase enrichment in space.
\end{abstract}

Key words. astrochemistry - molecular processes - methods: laboratory: solid state - ISM: molecules

\section{Introduction}

Acetylene, $\mathrm{C}_{2} \mathrm{H}_{2}$, has been found to be ubiquitous in the interstellar medium via gas phase detections in both emission and absorption, mostly around young stellar objects (Carr \& Najita 2008; Lahuis \& van Dishoeck 2000), as well as in molecular clouds (Lacy et al. 1989) and cometary comae (Mumma et al. 2003) indirectly supporting its existence in cometary ice. Pure solid state $\mathrm{C}_{2} \mathrm{H}_{2}$ has been found on Titan, both on the ground (Lara et al. 1996) and as ice particles in the atmosphere (Gudipati et al. 2011). In observational studies, it is used as a tracer for warm (100-1000 K) molecular gas (Sonnentrucker et al. 2007). Along many lines of sight, $\mathrm{C}_{2} \mathrm{H}_{2}$ gas phase abundances have been observed to be a few orders of magnitude higher than the predictions of cold-gas steady-state chemical models. Gas phase formation routes towards $\mathrm{C}_{2} \mathrm{H}_{2}$ are very slow leading to the conclusion that the enhanced abundances of $\mathrm{C}_{2} \mathrm{H}_{2}$ are likely due to sublimation from interstellar ices (Lahuis \& van Dishoeck 2000).

The infrared (IR) spectral features of solid state $\mathrm{C}_{2} \mathrm{H}_{2}$ are blended by much stronger features of $\mathrm{H}_{2} \mathrm{O}$, the dominant interstellar ice constituent (Knez et al. 2012). This makes direct observations of $\mathrm{C}_{2} \mathrm{H}_{2}$ in ices a major challenge, forcing observers to derive solid state abundances based on gas phase observations. Owing to the lack of a permanent dipole moment, gas phase $\mathrm{C}_{2} \mathrm{H}_{2}$ is radio-silent and therefore, its detection mainly relies on IR observations. From observations of warm gas in Cepheus A east, Sonnentrucker et al. (2007) derive abundances of $\mathrm{C}_{2} \mathrm{H}_{2}$ in interstellar ices of about 0.02 with respect to water. While in cometary comae (Mumma et al. 2003), fractions of 0.001 to 0.01 with respect to water have been derived. This makes $\mathrm{C}_{2} \mathrm{H}_{2}$ a small but non-negligible component of interstellar ices.

In chemical models, $\mathrm{C}_{2} \mathrm{H}_{2}$ is considered to be a starting point of a very complex gas phase photochemistry resulting in polymerization upon UV-induced dehydrogenation and addition reactions (Loison et al. 2014, and references therein). Linear carbon chain radicals have been detected in the surrounding environment of carbon stars (Cernicharo 2004) and are part of the UV haze in Titan's atmosphere (Gudipati et al. 2011, and references therein). The gas phase reaction pathways to the formation of carbon chain species have been studied well, which explains the variety of carbon chain species observed in space (Jolly \& Bénilan 2008).

Laboratory reserach of solid state $\mathrm{C}_{2} \mathrm{H}_{2}$ is generally limited to its pure form (Compagnini et al. 2009; Strazzulla et al. 2002; Zhou et al. 2009), while in an interstellar environment, $\mathrm{C}_{2} \mathrm{H}_{2}$ is expected to be present in a water-dominated environment with UV photons as the main chemical trigger. Studies of the VUV-induced solid state $\mathrm{C}_{2} \mathrm{H}_{2}$ photochemistry, especially when embedded in water water ice, therefore, provide vital information on solid state reactions yielding pathways towards molecular complexity in space.

In this paper, we present a systematic laboratory study of the VUV photochemistry of solid state $\mathrm{C}_{2} \mathrm{H}_{2}$ and $\mathrm{C}_{2} \mathrm{H}_{2}$ embedded in $\mathrm{H}_{2} \mathrm{O}$ ice by a multispectral in-situ approach that combines 
Fourier transform infrared (FTIR) with UV-VIS spectroscopy. The photoprocessing of the $\mathrm{C}_{2} \mathrm{H}_{2}$ ice is performed under conditions as in space, at low temperatures and VUV light that spectrally resembles the radiation field in dark clouds, i.e., light dominated by emissions from cosmic-ray-excited hydrogen.

\section{Experimental}

This study implements a stepwise approach to characterize the VUV photochemistry of $\mathrm{C}_{2} \mathrm{H}_{2}$. The first step consists of embedding the $\mathrm{C}_{2} \mathrm{H}_{2}$ molecules in an inert environment. With increasing complexity, it becomes more challenging to characterize the underlying reaction scheme.

The inert environment is achieved by isolating the $\mathrm{C}_{2} \mathrm{H}_{2}$ molecules in an argon matrix with 1:100 concentration. Although not astrophysically relevant, this enables us to track the initial reaction products while limiting the chance of reactions with radicals present inside the matrix. The second step consists of irradiating a pure $\mathrm{C}_{2} \mathrm{H}_{2}$ ice allowing reactions between $\mathrm{C}_{2} \mathrm{H}_{2}$ molecules and their photoproducts to take place. This results in a more complex reaction scheme since the radicals as detected in the argon matrix can recombine and form new, larger molecules. In the final step, a mixed $\mathrm{C}_{2} \mathrm{H}_{2}: \mathrm{H}_{2} \mathrm{O}$ ice is grown and VUV-photoprocessed.

In all these experiments, a multispectral approach is employed to detect the photochemical products, by combining two distinct in-situ spectroscopic techniques: UV-VIS spectroscopy and FTIR spectroscopy.

UV-VIS spectroscopy relies on the observation of electronic transitions in the 220-700 $\mathrm{nm}$ range. These transitions are typically very strong and molecule specific, facilitating identification of species present in concentrations of 1:10 000 and even lower, thereby enabling the detection of molecular species present in very low abundances. Moreover, matrix material (such as water) does not absorb in this domain and this helps in identifying spectral features of new reaction products. These, however, may overlap, hampering unambiguous identifications.

FTIR absorption spectroscopy enables us to observe the vibrational transitions, leading to a wealth of spectral features guiding identification of a multitude of reaction products present in sufficient abundances. The signal-to-noise ratio typically requires species to be present in a 1:100 fraction in order to identify them. These features may also overlap, specifically because comparable vibrational modes of different species may have rather similar absorption energies. Moreover, matrix material (specifically water) also absorbs in this range. Consequently, typically high concentrations are needed for detection. This is also the case for $\mathrm{C}_{2} \mathrm{H}_{2}: \mathrm{H}_{2} \mathrm{O}$ ices. Spectral overlap exists between $\mathrm{C}-\mathrm{H}$ and $\mathrm{O}-\mathrm{H}$ stretching and other modes, while the IR intensities of $\mathrm{H}_{2} \mathrm{O}$ are orders of magnitude higher than that of $\mathrm{C}_{2} \mathrm{H}_{2}$ (Knez et al. 2012). As a result, to detect $\mathrm{C}_{2} \mathrm{H}_{2}$ in a water environment using our setup, a ratio of 1:10 or higher is required. This requirement fixes the concentration used throughout the experiment, but it should be noted that in an astrophysical environment, the $\mathrm{C}_{2} \mathrm{H}_{2}$ abundances are lower.

In our laboratory, both measurement methodologies are implemented in two distinct setups. The measurements using UV-VIS spectroscopy are performed using our optical absorption setup for ice spectroscopy (OASIS), while the infrared absorption spectroscopic data are obtained using a FTIR high vacuum (HV) setup. The ice temperature of $12 \mathrm{~K}$ is used throughout all experiments as it is towards the lower limit of temperatures in interstellar ices that are in the range of $10-50 \mathrm{~K}$ (Boogert et al. 2008, and references therein). Additionally, the desorption temperature of argon is around $35 \mathrm{~K}$ requiring the use of temperatures sufficiently below that point to prevent unwanted desorption.

\subsection{OASIS}

OASIS has been described in detail in Allodi et al. (2013) and Bouwman et al. (2009). It consists of a high vacuum chamber $\left(P<3 \times 10^{-7}\right.$ mbar $)$ inside which a $\mathrm{MgF}_{2}$ ice deposition window is suspended on the cold finger of a closed cycle helium cryostat. A Lakeshore 330 temperature controller holds the temperature of the deposition window at the desired level in the range of 12 to $325 \mathrm{~K}$ with an absolute accuracy of better than $1 \mathrm{~K}$, using a resistive heater.

The ice material is provided in the gas phase from an external glass bulb. It is guided through a $6 \mathrm{~mm}$ diameter stainless steel tube ending at a distance of $30 \mathrm{~mm}$ perpendicular to the deposition window inside the chamber. Between the bulb and the deposition window, a leak valve is installed and used to control the deposition rate. The thickness of the ice is monitored by measuring the interference pattern of a HeNe laser beam reflected off the ice surface and the deposition window while the ice grows. The ice growth causes a pathlength difference between the two reflections, yielding optical interference and modulating the intensity by $\sim 20 \%$ over time. This method of measuring ice thickness is routine, (Romanescu et al. 2009; Bossa et al. 2014) and for our specific case, it has been described by Bouwman et al. (2009). The ice thickness information is used to guarantee reproducible conditions between different measurements.

The interstellar UV field is simulated by a microwavepowered $\mathrm{H}_{2}$ discharge lamp that mainly produces Ly- $\alpha$ photons at $121.6 \mathrm{~nm}$ with a broadband emission centred on $160 \mathrm{~nm}$ (Chen et al. 2014). This lamp is shared between both experimental setups for optimal consistency between the measurements. The operational pressure of the $\mathrm{H}_{2}$ lamp is kept constant at 0.4 mbar. The absolute UV photon flux is calibrated using $\mathrm{O}_{2}$ actinometry as described by Cottin et al. (2003). This mechanism involves the formation of $\mathrm{O}_{3}$ upon the photoirradiation of $\mathrm{O}_{2}$ ice for which the yield is known (Cottin et al. 2003). Cottin et al. (2003) propose a correction factor of 3.1 to take the difference in yield between the gas phase values as obtained by Okabe (1978) and the actual solid state value into account. This factor is used in this calibration. The $\mathrm{O}_{3}$ column density is derived from the strong $\mathrm{O}_{3}$ absorption feature centered at $259 \mathrm{~nm}$ which has an absorption cross section of $6 \times 10^{-17} \mathrm{~cm}^{2}$ molecule ${ }^{-1}$ (Jones et al. 2014). In the present OASIS experiment, this method yields a VUV photon flux of $7.9 \pm 1.6 \times 10^{12}$ photons $\mathrm{cm}^{-2} \mathrm{~s}^{-1}$ at the sample with a distance of $152 \mathrm{~mm}$ from the lamp to the deposition window. It should be noted that this UV flux value is lower than values mentioned earlier by Bouwman et al. (2009) and Cuylle et al. (2012). This results from a combination of window degradation with time and a possible overestimation of the photon flux in earlier reported studies.

During photoirradiation, the ice is monitored in quasi real time using a UV-VIS spectrometer (Andor Shamrock SR-303). The white light (200-800 nm) of a Xe arc lamp (LOT-Oriel) passes through two irises and is focused on the deposition window. The transmitted light passes through a third iris and is refocused onto the entrance slit of the spectrometer. With a 150 lines/mm grating the light is dispersed onto a CCD detector with 1024 pixels, providing spectral coverage from about 210 to $700 \mathrm{~nm}$ with a spectral resolution of $0.55 \mathrm{~nm}$. The spectral resolution can be improved at the expense of spectral range by using a different grating. During the measurements, multiple 
spectra are taken and averaged to improve signal-to-noise. In practice, a spectrum is generated every $10 \mathrm{~s}$ and is the result of averaging 112 exposures. The first spectrum is taken as a reference $\left(I_{O}\right)$, with which all subsequent spectra $(I)$ are converted in absorbance scale $\left(\right.$ absorbance $\left.=\ln \left(I / I_{O}\right)\right)$. The chamber pressure and window temperature are also recorded and stored.

\subsection{The FTIR HV setup}

The FTIR HV setup (Gerakines et al. 1995 and Bouwman et al. $2007)$ consists of a high vacuum chamber $\left(P<1 \times 10^{-7}\right.$ mbar $)$ inside which a $\mathrm{KBr}$ ice deposition window is mounted on the cold head of a closed cycle helium cryostat. The temperature of the deposition window can be controlled between 12 and $325 \mathrm{~K}$ with $1 \mathrm{~K}$ absolute accuracy by a Lakeshore 330 temperature controller. The temperature is controlled through a wire heater wound around the cryostat cold head and kept at $12 \mathrm{~K}$. The ice matrix is provided from an external glass bulb connected to a stainless steel $6 \mathrm{~mm}$ diameter deposition tube ending perpendicular to the deposition window at a distance of $\sim 50 \mathrm{~mm}$.

The ice is monitored during deposition and VUV irradiation using a varian FTIR spectrometer with a spectral range of $500-4000 \mathrm{~cm}^{-1}$ and $0.5 \mathrm{~cm}^{-1}$ spectral resolution. During deposition, the spectrometer is operated in direct mode and provides a new spectrum every three to four seconds. During VUV irradiation, 256 scans are added, requiring $\sim 15$ min to generate a spectrum with a substantially improved signal-to-noise ratio.

The interstellar UV field is simulated by the aforementioned $\mathrm{H}_{2}$ discharge lamp. Its VUV flux is determined on OASIS and the only difference between both setups is the distance from the lamp to the deposition window. The VUV flux can therefore be determined by applying the square law with distance to the deposition window. In this setup, the distance between the lamp and the deposition window is $56 \mathrm{~mm}$ yielding a distance ratio of 2.66. This yields a flux of $5.6 \pm 1.1 \times 10^{13}$ photons $\mathrm{cm}^{-2} \mathrm{~s}^{-1}$.

\section{3. $\mathrm{C}_{2} \mathrm{H}_{2}$ matrix material}

Three different gas samples are used to prepare the ice matrices. The first sample is obtained starting from purified welding gas which is $\mathrm{C}_{2} \mathrm{H}_{2}$ mixed with acetone $\left(\mathrm{C}_{3} \mathrm{H}_{6} \mathrm{O}\right)$. These gas components can be separated by using the difference in sublimation temperatures. The purity of the resulting $\mathrm{C}_{2} \mathrm{H}_{2}$ is checked in OASIS by a quadrupole mass spectrometer and in the FTIR HV setup from the IR spectrum. In both cases, neither acetone nor any other pollutants are observed, resulting in less than $0.1 \%$ impurities. This sample is the basis for the 1:10 mixture with $\mathrm{H}_{2} \mathrm{O}$. In this mixture, the $\mathrm{H}_{2} \mathrm{O}$ (milli-Q) has been subject to three freeze-pump-thaw cycles prior to mixing in a glass mixing line. The second sample of pure $\mathrm{C}_{2} \mathrm{H}_{2}$ starts from a commercial mixture of $\mathrm{C}_{2} \mathrm{H}_{2}$ : $\mathrm{He}(1: 100)$ with purity $99.2 \%$. Helium does not freeze onto the deposition window at $12 \mathrm{~K}$ while $\mathrm{C}_{2} \mathrm{H}_{2}$ does. This way, a nearly pure $\mathrm{C}_{2} \mathrm{H}_{2}$ ice can be grown, which is confirmed by the FTIR deposition spectra. Finally, the Ar: $\mathrm{C}_{2} \mathrm{H}_{2}$ measurements are performed by depositing a commercial 1:100:100 $\mathrm{C}_{2} \mathrm{H}_{2}: \mathrm{He}$ :Ar mixture with purity $99.2 \%$. In this way a 100:1 Ar: $\mathrm{C}_{2} \mathrm{H}_{2}$ ice is obtained providing the $\mathrm{C}_{2} \mathrm{H}_{2}$ isolated in an argon matrix.

\section{Results and discussion}

Figure 1 shows the FTIR deposition spectra for all three samples. In the upper panel, $\mathrm{C}_{2} \mathrm{H}_{2}$ is embedded in an argon matrix,

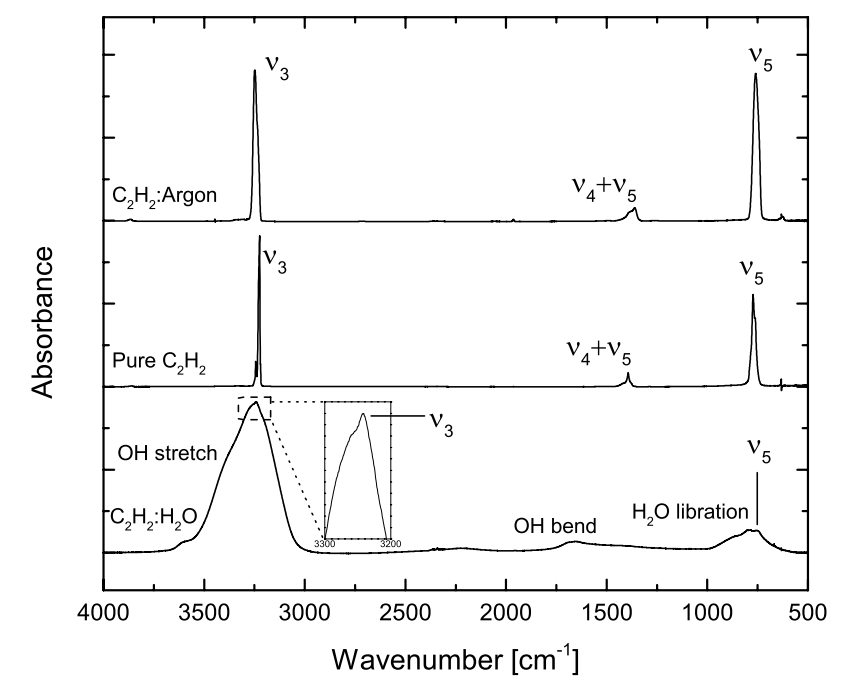

Fig. 1. IR spectra from $4000 \mathrm{~cm}^{-1}$ to $500 \mathrm{~cm}^{-1}$ of Ar: $\mathrm{C}_{2} \mathrm{H}_{2}$ 100:1 (top), pure $\mathrm{C}_{2} \mathrm{H}_{2}$ (middle) and $\mathrm{H}_{2} \mathrm{O}: \mathrm{C}_{2} \mathrm{H}_{2}$ 10:1 (bottom) at $12 \mathrm{~K}$. In the bottom panel, a zoom of the $\mathrm{OH}$ and $\mathrm{CH}$ stretching region is added to reveal the weak $\mathrm{CH}$ stretching mode of $\mathrm{C}_{2} \mathrm{H}_{2}$.

in the middle panel, pure acetylene is shown and the lower panel shows acetylene in water ice. Consistent with Knez et al. (2012), the spectra of $\mathrm{C}_{2} \mathrm{H}_{2}$ are dominated by three strong peaks and several weak features. The three strongest features are the $v_{3} \mathrm{C}-\mathrm{H}$ stretching mode around $3240 \mathrm{~cm}^{-1}$, the $v_{5} \mathrm{C}-\mathrm{H}$ bending mode around $760 \mathrm{~cm}^{-1}$, and the $v_{4}+v_{5}$ combination mode around $1370 \mathrm{~cm}^{-1}$. Among the three spectra, the $\mathrm{C}_{2} \mathrm{H}_{2}$ features shift by a few tens of $\mathrm{cm}^{-1}$ owing to the different matrix environments. The lack of water or any other features in the top and middle spectra proves the high purity of the samples. When using the 1:10 mixture, the strong overlap between spectral features of $\mathrm{C}_{2} \mathrm{H}_{2}$ and $\mathrm{H}_{2} \mathrm{O}$ results in water dominating the spectra. The bands related to $\mathrm{C}_{2} \mathrm{H}_{2}$ appear as a small superposition on the very strong and broad water bands. A summary of the features observed in the deposition spectra can be found in Table 1 .

Trace amounts of $\mathrm{H}_{2} \mathrm{O}$ are present inside the setup and become visible with time when water gradually deposits on top of the ice. This adds a baseline to the IR spectra, and may upon VUV irradiation have a chemical interaction with the top ice layer.

\section{1. $\mathrm{Ar}: \mathrm{C}_{2} \mathrm{H}_{2}$ results}

Isolating $\mathrm{C}_{2} \mathrm{H}_{2}$ in an argon matrix is a first step towards understanding the $\mathrm{C}_{2} \mathrm{H}_{2}$ photochemistry. It restricts chemical interactions to the primary interactions only, because in most cases, there is no other molecule or radical in range that effectively results in the stabilization of the radicals formed inside the matrix. In our case, $\sim 90 \%$ of the $\mathrm{C}_{2} \mathrm{H}_{2}$ molecules are isolated in the matrix, while the rest exist as small clusters (Behringer 1958).

The FTIR spectra of irradiated $\mathrm{C}_{2} \mathrm{H}_{2}$ in an Ar matrix (Fig. 2) reveal only a limited destruction fraction $(\sim 5 \%)$ of $\mathrm{C}_{2} \mathrm{H}_{2}$ after a fluence of $1.1 \times 10^{18}$ photons $\mathrm{cm}^{-2}$. As mentioned above, a baseline resulting from the background deposition of $\mathrm{H}_{2} \mathrm{O}$ appears with time. No obvious IR features attributed to the photodissociation products of $\mathrm{C}_{2} \mathrm{H}_{2}$ (e.g. $\mathrm{CH}, \mathrm{C}_{2} \mathrm{H}$ ) are found in our spectra, except for two very weak features observed at $3452 \mathrm{~cm}^{-1}$ and $3428 \mathrm{~cm}^{-1}$, which may be due to $\mathrm{OH}$ radicals (Acquista et al. 1968) and consistent with observations of OH in the UV-VIS spectra that are discussed below. 
Table 1. IR assignments of $\mathrm{C}_{2} \mathrm{H}_{2}$ and $\mathrm{H}_{2} \mathrm{O}$ features in the deposition spectra.

\begin{tabular}{lcccc}
\hline \hline Assignment & $\begin{array}{c}\text { Literature value } \\
\mathrm{cm}^{-1}\end{array}$ & $\begin{array}{c}\mathrm{Pure}_{2} \mathrm{H}_{2} \\
\mathrm{~cm}^{-1}\end{array}$ & $\begin{array}{c}\mathrm{C}_{2} \mathrm{H}_{2}: \mathrm{Ar} \\
\mathrm{cm}^{-1}\end{array}$ & $\begin{array}{c}\mathrm{C}_{2} \mathrm{H}_{2}: \mathrm{H}_{2} \mathrm{O} \\
\mathrm{cm}^{-1}\end{array}$ \\
\hline $\mathrm{C}_{2} \mathrm{H}_{2} \mathrm{CH}$ stretch $v_{3}$ & $3239^{a}$ & 3224 & 3249 & 3241 \\
$\mathrm{C}_{2} \mathrm{H}_{2}$ combination mode $v_{4}+v_{5}$ & $1371^{a}$ & 1393 & 1361 & 1388 \\
$\mathrm{C}_{2} \mathrm{H}_{2} \mathrm{CH}$ bending $v_{5}$ & $743^{a}$ & 773 & 761 & 757 \\
$\mathrm{H}_{2} \mathrm{O}$ OH stretch & $3280^{b}$ & - & - & 3253 \\
$\mathrm{H}_{2} \mathrm{O}$ OH bending & $1660^{b}$ & - & - & 1655 \\
$\mathrm{H}_{2} \mathrm{O}$ OH libration & $760^{b}$ & - & - & 801 \\
\hline
\end{tabular}

Notes. ${ }^{(a)}$ Knez et al. (2012); ${ }^{(b)}$ Gerakines et al. (1995).

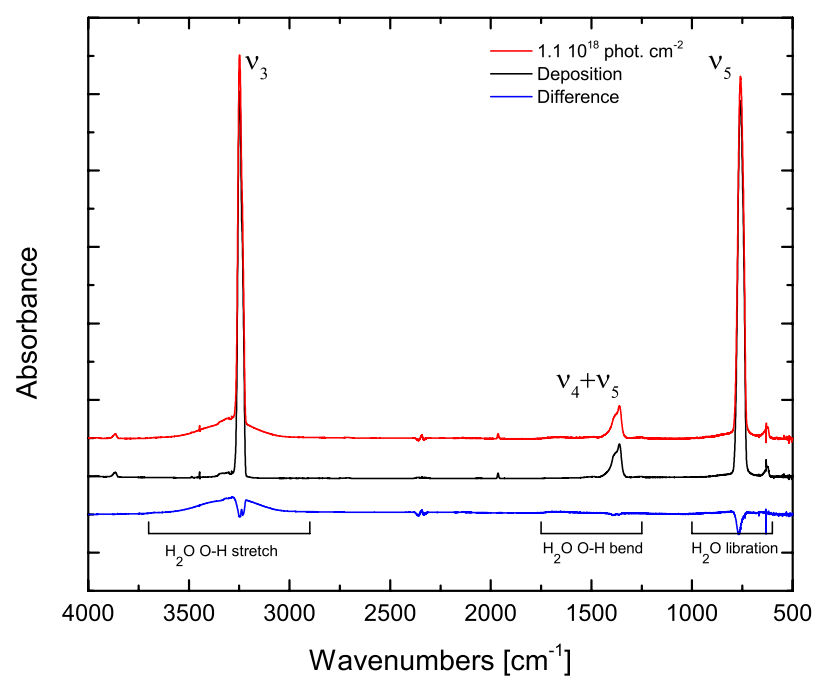

Fig. 2. IR spectra from $4000 \mathrm{~cm}^{-1}$ to $500 \mathrm{~cm}^{-1}$ of $\mathrm{Ar}: \mathrm{C}_{2} \mathrm{H}_{2}$ 100:1 under VUV irradiation. The top spectra are the spectra after irradiation with $1.1 \times 10^{18}$ photons, the middle spectrum is the deposition spectrum while the bottom spectrum is the difference between both. Note the background deposited water and the limited destruction of $\mathrm{C}_{2} \mathrm{H}_{2}$.

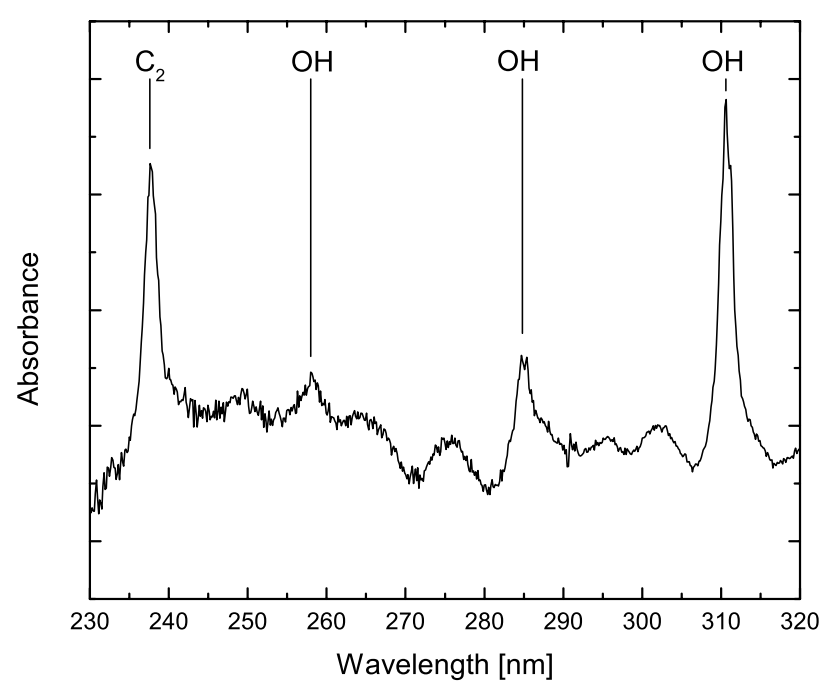

Fig. 3. UV-VIS spectra of Ar: $\mathrm{C}_{2} \mathrm{H}_{2}$ 100:1 under VUV irradiation.

The corresponding measurements in the UV-VIS domain reveal the gradual appearance of four bands upon VUV irradiation (Fig. 3). The signal-to-noise level is limited, mainly because of optical interference. A feature at $310.6 \mathrm{~nm}$ is accompanied by a second feature at $285.7 \mathrm{~nm}$ and a very weak feature at $258.1 \mathrm{~nm}$ gradually appearing over time. The first two features are potentially due to $\mathrm{C}_{2} \mathrm{H}$ (Graham et al. 1974) or $\mathrm{OH}$ (Pellerin et al. 1996) as a photoproduct of background deposited water. The experiment is therefore repeated without deposition of any matrix (and therefore only background deposition). This experiment features both stronger peaks and a hint of the third peak leading to the conclusion that these three peaks are a result of the $\mathrm{A}^{2} \Sigma^{+}(v=0,1,2) \leftarrow X^{2} \Pi(v=0)$ transitions of $\mathrm{OH}$. The last peak observed at $237.6 \mathrm{~nm}$ does not appear in the blank measurement, showing its origin as a photoproduct of $\mathrm{C}_{2} \mathrm{H}_{2}$. Based on Milligan et al. (1967), it can be attributed to the $(0,0)$ band of the Mulliken system of $\mathrm{C}_{2}\left(\mathrm{D}^{1} \Sigma_{u}^{+}-\mathrm{X}^{1} \Sigma_{q}^{+}\right)$.

Similar experiments have been performed before by Chang \& Graham (1982); Graham et al. (1974), and Milligan et al. (1967). Specifically, the observations of Chang \& Graham (1982) provide an intimate view on the photochemistry of $\mathrm{C}_{2} \mathrm{H}_{2}$ embedded in an argon matrix. Using UV spectroscopy in the range of $130-300 \mathrm{~nm}, \mathrm{C}_{2}, \mathrm{C}_{2} \mathrm{H}$ and $\mathrm{C}_{4} \mathrm{H}_{2}$ were observed as the main reaction products. Although no photon fluence was given, we note that, the $237.6 \mathrm{~nm}$ peak is found to be saturated in their experiment, which is only about $1 \%$ absorption in ours. This indicates that the photon fluence in Chang \& Graham (1982) must have been substantially higher. The lower radiation fluence in our experiment is consistent with the non-detection of $\mathrm{C}_{2} \mathrm{H}$ and $\mathrm{C}_{4} \mathrm{H}_{2}$.

\subsection{Pure $\mathrm{C}_{2} \mathrm{H}_{2}$ results}

Figures 4-6 show the FTIR and UV-VIS spectra of irradiated pure $\mathrm{C}_{2} \mathrm{H}_{2}$ ice. From the partial disappearance of the three strongest IR peaks, it is concluded that the photoirradiation of $\mathrm{C}_{2} \mathrm{H}_{2}$ with a fluence of $1.1 \times 10^{18}$ photons $\mathrm{cm}^{-2}$ leads to destruction of about $50 \%$ of the initially deposited $\mathrm{C}_{2} \mathrm{H}_{2}$. In all spectra, a wealth of new features appears.

\subsubsection{Polymerization}

Upon VUV irradiation of pure $\mathrm{C}_{2} \mathrm{H}_{2}$ ice, the production of short polyynes can be identified in the FTIR spectra. Two IR features at $\sim 3277$ and $1243 \mathrm{~cm}^{-1}$ (Fig. 4, marked as (1) and (2)) and tentatively a third one at $1010 \mathrm{~cm}^{-1}$, partially overlaping with other bands are visible. A zoom of these features in Fig. 5 reveals their structure in more detail. These features are assigned to $\mathrm{C}_{4} \mathrm{H}_{2}$ (Khlifi et al. 1995).

Further polymerization can be observed from the feature at $1234 \mathrm{~cm}^{-1}$ (Fig. 5), which can be identified as $\mathrm{C}_{6} \mathrm{H}_{2}, \mathrm{C}_{8} \mathrm{H}_{2}$ or longer (Shindo et al. 2001, 2003). The aforementioned reaction products have known vibrational transitions both in the short wavelength range of the $\mathrm{C}-\mathrm{H}$ stretching mode and around the C-H bending mode. Shindo et al. $(2001,2003)$ and 
S. H. Cuylle et al.: Vacuum ultraviolet photochemistry of solid acetylene: a multispectral approach

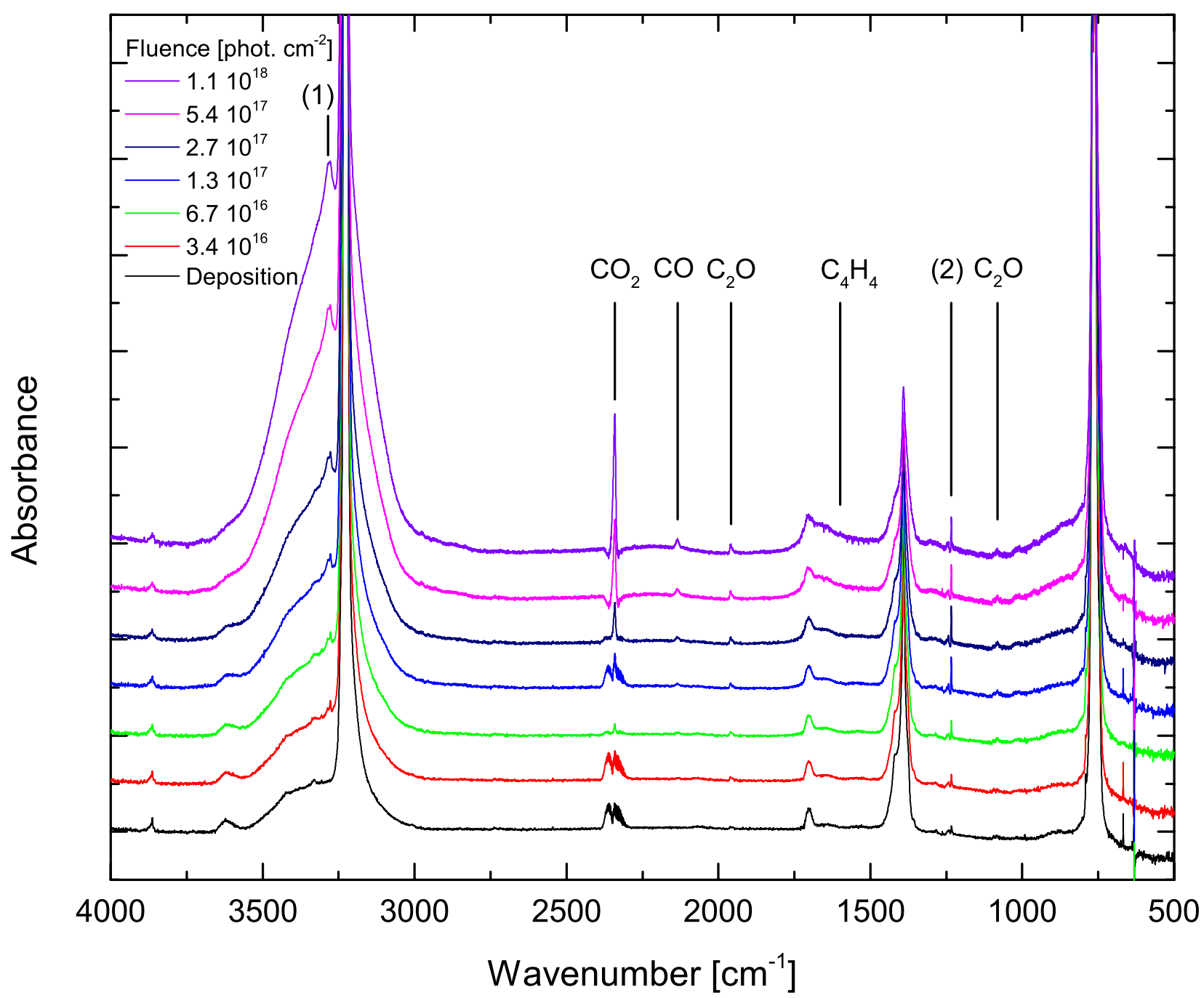

Fig. 4. IR spectra from $4000 \mathrm{~cm}^{-1}$ to $500 \mathrm{~cm}^{-1}$ of pure $\mathrm{C}_{2} \mathrm{H}_{2}$ under VUV irradiation. The strongest photoproduct features are indicated, and the features marked (1) and (2) are zoomed in in Fig. 5.

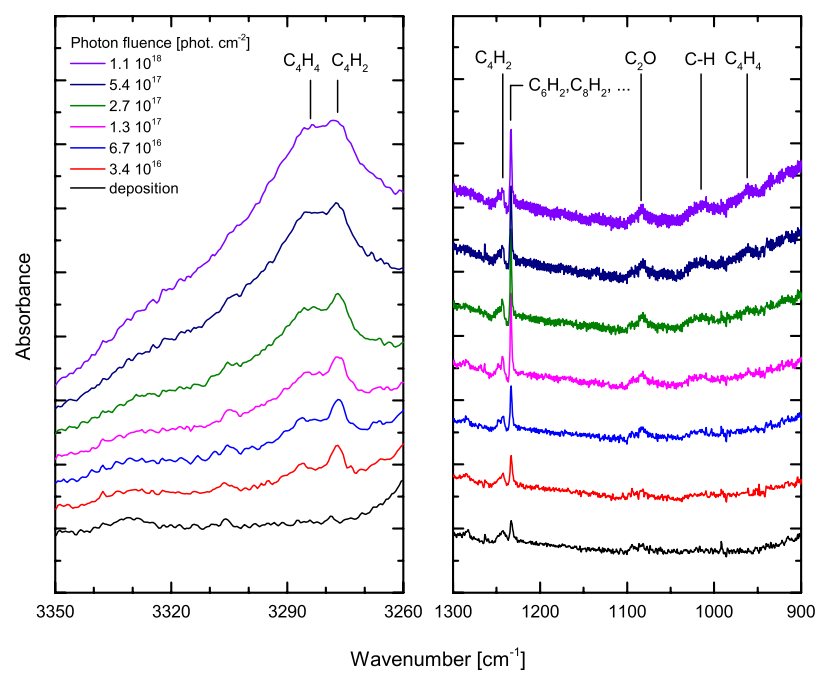

Fig. 5. Selected details of the IR spectra of pure $\mathrm{C}_{2} \mathrm{H}_{2}$ under VUV irradiation.

Zhou et al. (2009) have observed other stronger features at 600 , $\sim 620,664, \sim 3330$, and $3386 \mathrm{~cm}^{-1}$. Owing to a combination of the water baseline and worsened signal-to-noise ratios in these parts of the spectrum, these features are not unambiguously identified in our spectra. Table 2 provides a summary of the IR features, assignments and their literature values.

A typical aspect of polyynes of $\mathrm{C}_{6} \mathrm{H}_{2}$ and longer ones is that the IR transitions remain at nearly the same location. This hampers their individual identification (Jolly \& Bénilan 2008). Here, the combination of FTIR spectroscopy with UVVIS spectroscopy provides complementary information for identifying photoproducts, since the absorption features in the UVVIS provide better uniqueness, allowing for easier identification (Kloster-Jensen et al. 1974; Grutter et al. 1998).

The UV-VIS spectra of the irradiated $\mathrm{C}_{2} \mathrm{H}_{2}$ ice are dominated by two very strong bands at $219 \mathrm{~nm}$ and at $228 \mathrm{~nm}$ and a very broad wing with weak, unresolved features up to $400 \mathrm{~nm}$ (Fig. 6). A third peak at $209.5 \mathrm{~nm}$ appears in repeated experiments that are not shown here. The origin of these peaks is not a priori clear, although similar studies can provide very useful insight into their identification. VUV irradiation of $\mathrm{C}_{2} \mathrm{H}_{2}$ embedded in noble gas matrix by Wu \& Cheng (2008) yielded polyynes $\left(\mathrm{H}(-\mathrm{C} \equiv \mathrm{C}-)_{m} \mathrm{H}\right)$ up to $\mathrm{C}_{8} \mathrm{H}_{2}$ and linear carbon chains $\left(\mathrm{C}_{m}\right)$ up to $\mathrm{C}_{8}$. From this, one would expect that when a pure $\mathrm{C}_{2} \mathrm{H}_{2}$ ice is irradiated, polymerization will result in the formation of similar molecules (e.g. $\mathrm{H}(-\mathrm{C} \equiv \mathrm{C}-)_{m} \mathrm{H}, \mathrm{H}(-\mathrm{C} \equiv \mathrm{C})_{m}$ or $\left.(\mathrm{C} \equiv \mathrm{C})_{m}\right)$. 
Table 2. IR assignments of VUV photoproducts and comparison with the literature values over all three matrix types.

\begin{tabular}{lcccc}
\hline \hline Feature & $\begin{array}{c}\text { Literature } \\
\mathrm{cm}^{-1}\end{array}$ & $\begin{array}{c}\text { Pure } \mathrm{C}_{2} \mathrm{H}_{2} \\
\mathrm{~cm}^{-1}\end{array}$ & $\begin{array}{c}\mathrm{C}_{2} \mathrm{H}_{2}: \mathrm{Ar} \\
\mathrm{cm}^{-1}\end{array}$ & $\begin{array}{c}\mathrm{C}_{2} \mathrm{H}_{2}: \mathrm{H}_{2} \mathrm{O} \\
\mathrm{cm}^{-2}\end{array}$ \\
\hline $\mathrm{OH}^{a}$ & 3452 & - & 3452 & - \\
$\mathrm{C}_{4} \mathrm{H}_{4}{ }^{b}$ & 3284 & 3284 & - & - \\
$\mathrm{C}_{4} \mathrm{H}_{2}{ }^{c}$ & 3277 & 3277 & - & - \\
$\mathrm{OH}^{a}$ & 3248 & - & 3248 & - \\
$\mathrm{CO}_{2}{ }^{d}$ & 2347 & 2341 & - & 2347 \\
$\mathrm{CO}^{d}$ & 2141 & 2134 & - & 2141 \\
$\mathrm{C}_{2} \mathrm{O}^{e}$ & 1962 & 1959 & - & - \\
$\mathrm{H}_{2} \mathrm{CO}^{f}$ & $1727+$ wing & - & - & $1711-1680$ \\
$\mathrm{C}_{4} \mathrm{H}_{4}{ }^{a}$ & 1599 & 1599 & - & - \\
$\mathrm{H}_{2} \mathrm{CO}^{f}$ & 1498 & - & - & 1496 \\
$\mathrm{CH}_{3} \mathrm{OH}^{g}$ & 1452 & - & - & 1435 \\
$\mathrm{CH}_{4}{ }^{f}$ & 1301 & - & - & 1303 \\
$\mathrm{C}_{4} \mathrm{H}_{2}{ }^{h}$ & $1248-1243$ & 1243 & - & - \\
$\mathrm{C}_{6} \mathrm{H}_{2}, \mathrm{C}_{8} \mathrm{H}_{2}, \ldots$ & $i$ & 1234 & - & 1233 \\
$\mathrm{C}_{2} \mathrm{O}^{e}$ & $1237-1229,1232-1226$ & 1081 & - & - \\
$\mathrm{CH}_{3} \mathrm{OH}^{g}$ & 1081 & - & - & 1019 \\
$\mathrm{C}_{4} \mathrm{H}_{2}{ }^{c}$ & 1032 & $1020(\mathrm{t})$. & - & - \\
$\mathrm{C}_{4} \mathrm{H}_{4}{ }^{b}$ & 1010 & 979 & - & - \\
\hline
\end{tabular}

Notes. Locations indicated with “_” did not reveal any of the photoproducts. ${ }^{(a)}$ Acquista et al. (1968); ${ }^{(b)}$ Kim \& Kaiser (2009); ${ }^{(c)}$ Zhou et al. (2009); ${ }^{(d)}$ Gerakines et al. (1995); ${ }^{(e)}$ Jacox et al. (1965); ${ }^{(f)}$ Öberg et al. (2009); ${ }^{(g)}$ Falck \& Whalley (1961); ${ }^{(h)}$ Khlifi et al. $(1995) ;{ }^{(i)}$ Shindo et al. (2001, 2003).

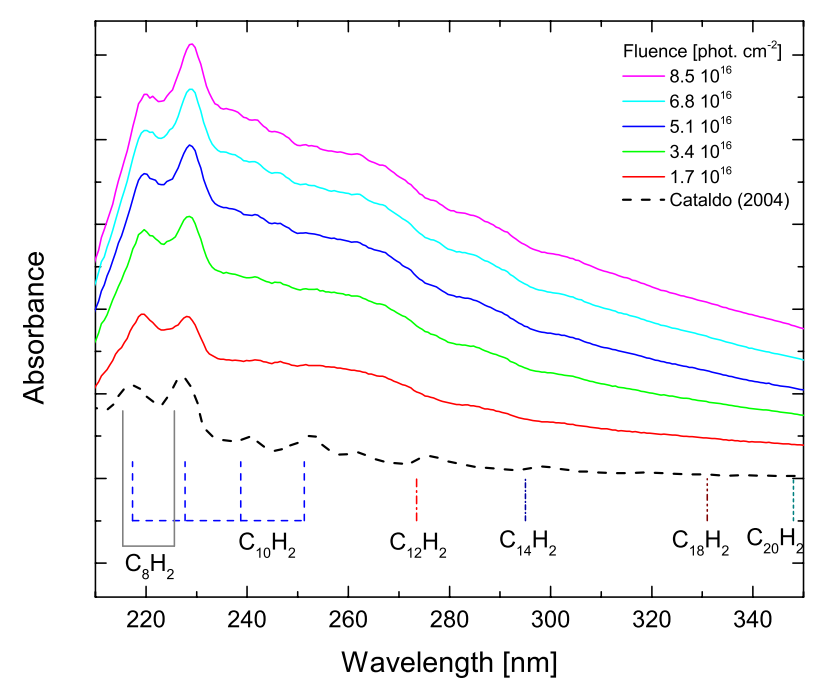

Fig. 6. UV-VIS spectra of pure $\mathrm{C}_{2} \mathrm{H}_{2}$ under VUV irradiation, polyyne feature values are solution values obtained from Kloster-Jensen et al. (1974). The bottom trace shows the remarkably similar spectra obtained by Cataldo (2004).

Comparing our UV-VIS spectra to spectra obtained by arcing of graphitic electrodes submerged in water (Cataldo 2004), also shown in Fig. 6, a remarkable similarity appears. The spectra from Cataldo (2004) are also dominated by two strong peaks associated with a broad, partially resolved wing up to $400 \mathrm{~nm}$. High-performance liquid-chromatography (HPLC) analysis revealed the spectra obtained by Cataldo (2004) to be due to polyynes in the $\mathrm{C}_{6} \mathrm{H}_{2}-\mathrm{C}_{16} \mathrm{H}_{2}$ range, although no spectroscopic assignments were made. The UV-VIS spectra of polyynes typically feature the ${ }^{1} \Sigma_{u}^{+} \leftarrow{ }^{1} \Sigma_{g}^{+}$as the strongest transition accompanied by multiple vibronic progressions (Kloster-Jensen et al. 1974) towards the short wavelength side. On the long wavelength side of this system, two overlapping forbidden electronic transitions $\left({ }^{1} \Sigma_{u}^{-} \leftarrow{ }^{1} \Sigma_{g}^{+}\right.$and $\left.{ }^{1} \Delta_{u} \leftarrow{ }^{1} \Sigma_{g}^{+}\right)$and their vibronic

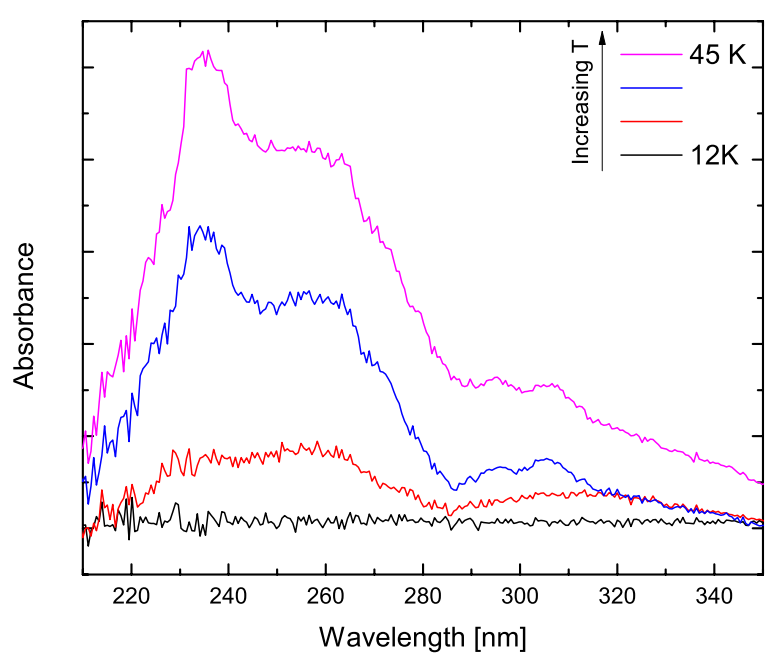

Fig. 7. UV-VIS spectra of pure $\mathrm{C}_{2} \mathrm{H}_{2}$ after VUV irradiation, during warmup.

progressions appear albeit with oscillator strengths that are three orders of magnitude smaller. When using the band assignments of liquid matrix polyynes as observed by Kloster-Jensen et al. (1974) to interpret our spectra (Fig. 6), the strongest signals are likely due to $\mathrm{C}_{8} \mathrm{H}_{2}$, with longer polyyne signals, possibly up to $\mathrm{C}_{20} \mathrm{H}_{2}$, hidden in the broad wing extending up to $400 \mathrm{~nm}$. This shows consistency in overall profile with our FTIR data where $\mathrm{C}_{8} \mathrm{H}_{2}$ is also observed.

A multitude of polyyne species are therefore the most probable explanation for the absorption features observed. Moreover, it has been found by Cataldo et al. (2008) that polyynes are the dominant product of the UV photochemistry of $\mathrm{C}_{2} \mathrm{H}_{2}$ suspended in liquid at room temperature.

In addition, the broad UV absorption feature is further investigated while slowly warming up the ice (Fig. 7). During warmup, separate absorption features in the 230-280 $\mathrm{nm}$ and 
S. H. Cuylle et al.: Vacuum ultraviolet photochemistry of solid acetylene: a multispectral approach

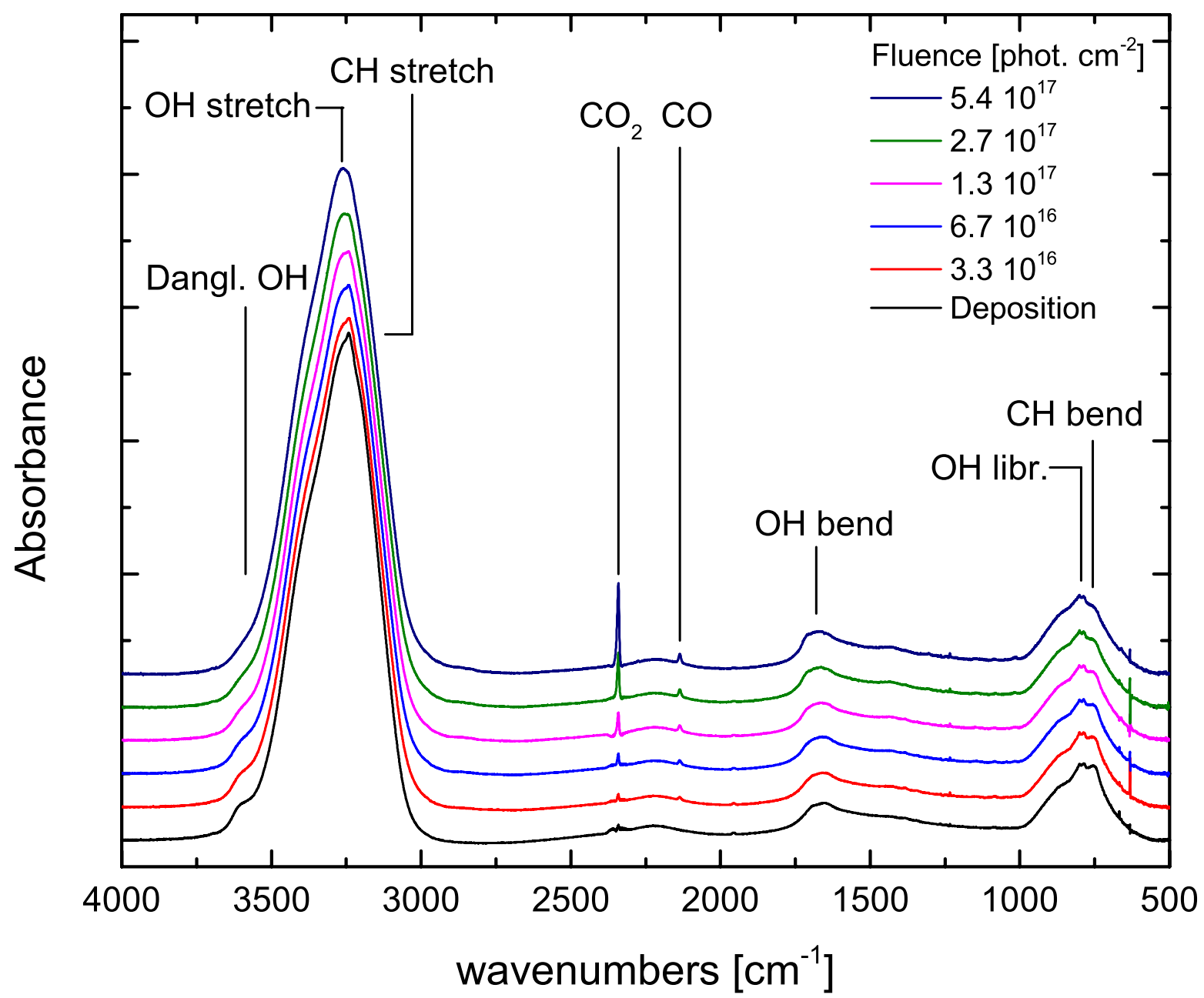

Fig. 8. IR spectra from $4000 \mathrm{~cm}^{-1}$ to $500 \mathrm{~cm}^{-1}$ of $\mathrm{C}_{2} \mathrm{H}_{2}: \mathrm{H}_{2} \mathrm{O}$ 1:10 under VUV irradiation. The deposition spectrum is identical to the bottom panel of Fig. 1.

in the 290-320 $\mathrm{nm}$ become visible, but there is no sign of existing features disappearing up to the point where the $\mathrm{C}_{2} \mathrm{H}_{2}$ matrix desorbs around $50 \mathrm{~K}$. This this shows that there is further enrichment of the ice with polyynes or polyyne-like species and when cross-referencing the new features with known absorption spectra of polyynes, there are indications of the formation of polyynes in the $\mathrm{C}_{8} \mathrm{H}_{2}-\mathrm{C}_{14} \mathrm{H}_{2}$ range. The exact thermal processing mechanism is unclear.

\subsubsection{Vinylacetylene}

During irradiation, features associated to small amounts of vinylacetylene $\left(\mathrm{C}_{4} \mathrm{H}_{4}\right)$ appear in the FTIR spectra at $3284 \mathrm{~cm}^{-1}$ (Fig. 5, left panel), at $1599 \mathrm{~cm}^{-1}$ and at $962 \mathrm{~cm}^{-1}$ (Fig. 5, right panel; Kim \& Kaiser 2009). The remarkable lack of more saturated alkanes in the spectra is different from observations by Strazzulla et al. (2002) after bombardment of $\mathrm{C}_{2} \mathrm{H}_{2}$ with $15 \mathrm{KeV}$ $\mathrm{N}^{+}$ions.

\subsubsection{Interaction of $\mathrm{C}_{2} \mathrm{H}_{2}$ with background deposited water}

The strongest new features appearing in the FTIR spectra of photoirradiated $\mathrm{C}_{2} \mathrm{H}_{2}$ (Fig. 4) are a result of interaction with the background deposited water. They typically appear in the $\mathrm{C}=\mathrm{O}$ stretching region ranging from roughly 1800 to $2500 \mathrm{~cm}^{-1}$. The strongest at $2341 \mathrm{~cm}^{-1}$ is associated to $\mathrm{CO}_{2}$. The $2134 \mathrm{~cm}^{-1}$ feature is related to $\mathrm{CO} . \mathrm{C}_{2} \mathrm{O}$ is identified, based on two features at $1959 \mathrm{~cm}^{-1}$ and at $1081 \mathrm{~cm}^{-1}$, and their relative intensities of about 7:1 (Jacox et al. 1965). A summary of the assignments is given in Table 2. The appearance of these molecular species shows a complex chemical interaction between $\mathrm{C}_{2} \mathrm{H}_{2}$ and $\mathrm{H}_{2} \mathrm{O}$ besides polymerization.

\section{3. $\mathrm{C}_{2} \mathrm{H}_{2}: \mathrm{H}_{2} \mathrm{O}$ results}

The photochemical interaction between $\mathrm{C}_{2} \mathrm{H}_{2}$ and $\mathrm{H}_{2} \mathrm{O}$ can be studied into more detail by embedding $\mathrm{C}_{2} \mathrm{H}_{2}$ in a $\mathrm{H}_{2} \mathrm{O}$ matrix in $1: 10$ ratio. This system is relevant for the bulk of interstellar solid $\mathrm{C}_{2} \mathrm{H}_{2}$ which is present in a water-dominated ice environment, although it should be noted that there the abundance is typically lower.

\subsubsection{Polymerization}

When irradiating the ice with VUV photons, some new features gradually appear in the spectra, simultaneously, the $\mathrm{C}_{2} \mathrm{H}_{2}$ peaks disappear (Fig. 8). Most of these features are the result of interaction with the water inside the matrix. The aforementioned feature at $1234 \mathrm{~cm}^{-1}$ can be seen in Fig. 9 and is associated to $\mathrm{C}_{6} \mathrm{H}_{2}, \mathrm{C}_{8} \mathrm{H}_{2}$ and longer polyynes. This feature appears after irradiation with $3.3 \times 10^{16}$ photons $\mathrm{cm}^{-1}$ and subsequently remains at the same intensity. Its strength is substantially less 


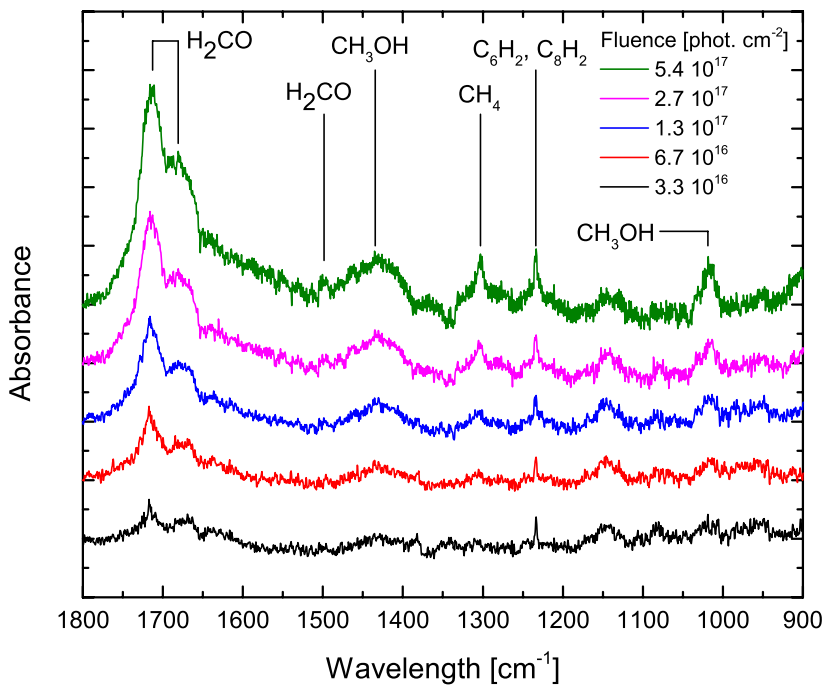

Fig. 9. Selected detail of the IR spectra of $\mathrm{C}_{2} \mathrm{H}_{2}: \mathrm{H}_{2} \mathrm{O} \quad 1: 10$ under VUV irradiation. These spectra are difference spectra (with an offset for each spectrum), meaning that all positive peaks that appear are photoproducts.

than in the observations with pure $\mathrm{C}_{2} \mathrm{H}_{2}$ ice, although its appearance shows that the formation of polyynes persists, even under stiff competition with water-related photoproducts. This observation shows a remarkable consistency with the UV-VIS spectra (Fig. 10) where the same broad absorption appears as with pure $\mathrm{C}_{2} \mathrm{H}_{2}$. Two peaks very similar to the ones appearing in irradiated pure $\mathrm{C}_{2} \mathrm{H}_{2}$ ice (Fig. 6) become visible, although significantly widened and slightly red-shifted, which is a typical water-matrix-induced effect. As in the IR, the feature grows to a radiation fluence of $3.4 \times 10^{16}$ photons $\mathrm{cm}^{-2}$ and subsequently remains, formally linking both spectral features to the same reaction products. This is consistent with the formation of polyynelike molecules in the $\mathrm{C}_{8} \mathrm{H}_{2}-\mathrm{C}_{14} \mathrm{H}_{2}$ range and shows their stability in a water-dominated environment.

\subsection{2. $\mathrm{C}_{2} \mathrm{H}_{2}$ photochemical reactions with $\mathrm{H}_{2} \mathrm{O}$}

The strongest new features appearing in the FTIR spectra (Fig. 8) are at $2347 \mathrm{~cm}^{-1}$ and at $2141 \mathrm{~cm}^{-1}$ and are due to $\mathrm{CO}_{2}$ and $\mathrm{CO}$, respectively. Besides these strong features, many weaker features appear in the range from 900 to $1800 \mathrm{~cm}^{-1}$ (Fig. 9). It should be noted that these spectra are relative to the deposition spectra (with offset); i.e., all features visible in the spectra are likely due to new reaction products.

Most of these can be assigned to reactions between $\mathrm{C}_{2} \mathrm{H}_{2}$ and water. The feature at $1710 \mathrm{~cm}^{-1}$ and the wing at $1679 \mathrm{~cm}^{-1}$ are typical of formaldehyde $\left(\mathrm{H}_{2} \mathrm{CO}\right)$ with a second feature at $1498 \mathrm{~cm}^{-1}$ also appearing (Öberg et al. 2009). The features at 1435 and $1019 \mathrm{~cm}^{-1}$ are due to methanol $\left(\mathrm{CH}_{3} \mathrm{OH}\right.$; Falck \& Whalley 1961), and the feature at $1303 \mathrm{~cm}^{-1}$ is from methane $\left(\mathrm{CH}_{4}\right.$; Öberg et al. 2009). The feature at $1234 \mathrm{~cm}^{-1}$ was discussed above. A similar study by Wu et al. (2002) reports on the photochemistry of a 1:4 $\mathrm{C}_{2} \mathrm{H}_{2}: \mathrm{H}_{2} \mathrm{O}$ ice with various wavelengths of vacuum UV radiation that includes Lyman- $\alpha$. However, assignments were limited to $\mathrm{CO}$ and $\mathrm{CO}_{2}$.

To assess the carbon budget inside the ice, a quantitative analysis of the formation of $\mathrm{CO}$ and $\mathrm{CO}_{2}$ is made based on the IR spectral data. From the integrated area of the $\mathrm{OH}$ stretching mode of water in the deposition spectrum, a water column

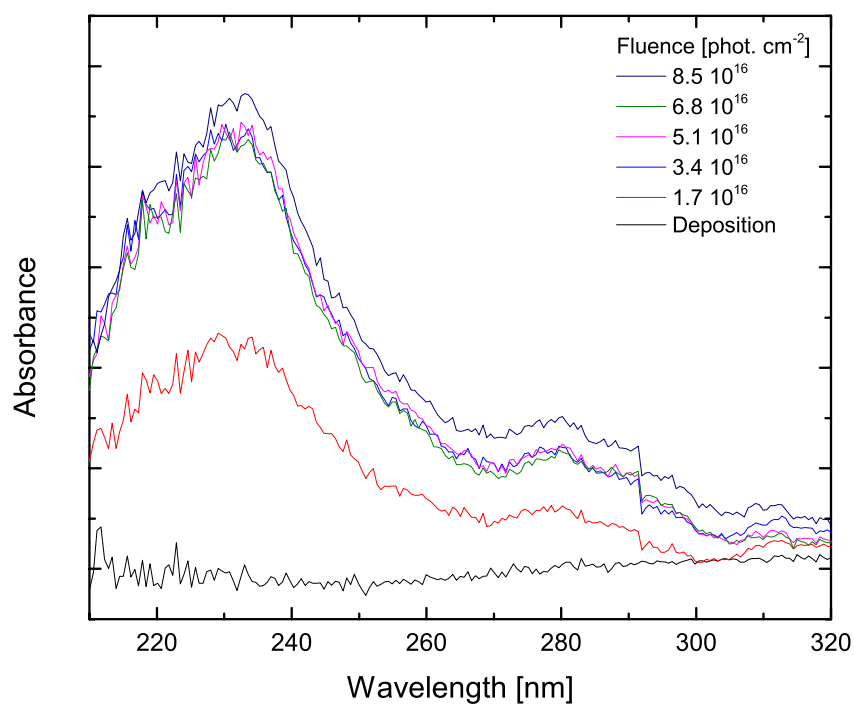

Fig. 10. UV-VIS spectra of $\mathrm{C}_{2} \mathrm{H}_{2}: \mathrm{H}_{2} \mathrm{O}$ 1:10 under VUV irradiation.

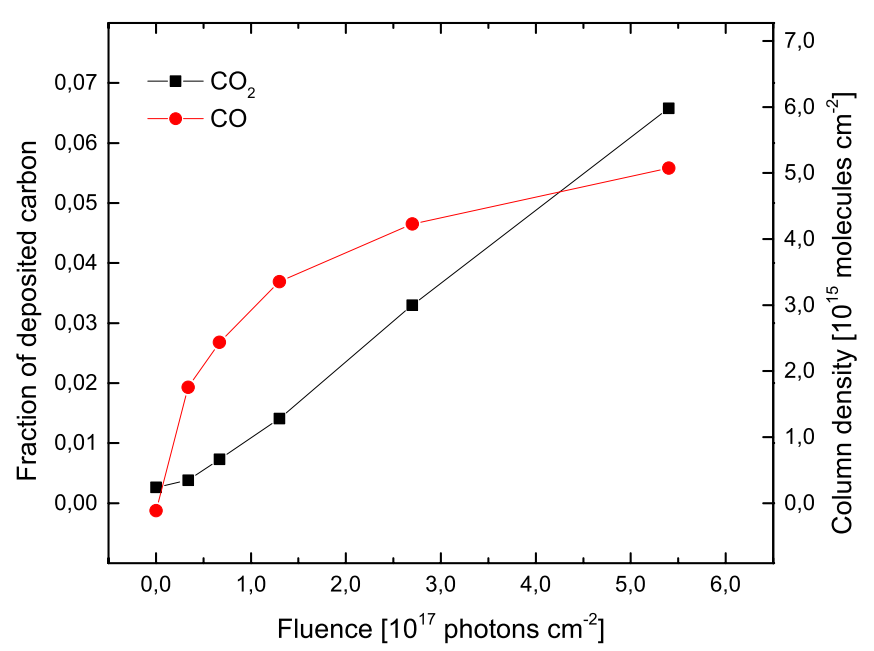

Fig. 11. Production of $\mathrm{CO}$ and $\mathrm{CO}_{2}$ upon VUV irradiation of a $\mathrm{C}_{2} \mathrm{H}_{2}: \mathrm{H}_{2} \mathrm{O} 1: 10$ ice as a function of total deposited carbon $\left(N_{\mathrm{CO}} /(2 \times\right.$ $\left.N_{\mathrm{C}_{2} \mathrm{H}_{2}}\right)$ and $\left.N_{\mathrm{CO}_{2}} /\left(2 \times N_{\mathrm{C}_{2} \mathrm{H}_{2}}\right)\right)$ and radiation fluence.

density of $\sim 5.5 \times 10^{17}$ molecules $\mathrm{cm}^{-2}$ is derived. Knowing the $\mathrm{C}_{2} \mathrm{H}_{2}$ fraction of $1: 10$, the amount of carbon is $\sim 1.1 \times 10^{17}$ atoms $\mathrm{cm}^{-2}$ (2 carbon atoms per $\mathrm{C}_{2} \mathrm{H}_{2}$ molecule). The amount of $\mathrm{CO}$ and $\mathrm{CO}_{2}$ is interpreted directly from their IR transition intensities and summarized in Fig. 11. After the final radiation fluence of $\sim 5.4 \times 10^{17}$ photons $\mathrm{cm}^{-2}$, about $12 \%$ of the initial carbon budget is stored in $\mathrm{CO}$ and $\mathrm{CO}_{2}$ molecules although all $\mathrm{C}_{2} \mathrm{H}_{2}$ has disappeared from the spectra. The formation rate of $\mathrm{CO}_{2}$ is linear with radiation fluence while for $\mathrm{CO}$, although initially dominant, the formation rate decreases with time. This is consistent with a view that, in a water-dominated environment, $\mathrm{CO}$ is the precursor for formation of $\mathrm{CO}_{2}, \mathrm{H}_{2} \mathrm{CO}$ and $\mathrm{CH}_{3} \mathrm{OH}$ upon VUV irradiation (Watanabe \& Kouchi 2002).

\subsection{Discussion}

The observations with both methods show a very consistent image of the role $\mathrm{C}_{2} \mathrm{H}_{2}$ plays in ice photochemistry. The photodissociation pathways of $\mathrm{C}_{2} \mathrm{H}_{2}$ were analyzed by 
Okabe (1975). The VUV lamp provides enough energy to overcome the threshold of five dissociation pathways:

\begin{tabular}{llll}
\hline \hline Reaction & & & Threshold \\
\hline $\mathrm{C}_{2} \mathrm{H}_{2}+h v \rightarrow \mathrm{C}_{2} \mathrm{H}+\mathrm{H}$ & $230.6 \mathrm{~nm}$ \\
$\mathrm{C}_{2} \mathrm{H}_{2}+h v \rightarrow \mathrm{C}_{2}+\mathrm{H}_{2}$ & $198.5 \mathrm{~nm}$ \\
$\mathrm{C}_{2} \mathrm{H}_{2}+h v \rightarrow \mathrm{C}_{2}\left(\mathrm{~A}^{3} \Pi\right)+\mathrm{H}_{2}$ & $142.2 \mathrm{~nm}$ \\
$\mathrm{C}_{2} \mathrm{H}_{2}+h v \rightarrow \mathrm{C}_{2}(\mathrm{~B}) \mathrm{H}+\mathrm{H}$ & $130.5 \mathrm{~nm}$ \\
$\mathrm{C}_{2} \mathrm{H}_{2}+h v \rightarrow 2 \times \mathrm{CH}$ & $125.3 \mathrm{~nm}$ \\
\hline
\end{tabular}

The VUV emission profile comprises Lyman-alpha radiation and a broadband component around $160 \mathrm{~nm}$ roughly in a 1:2 intensity ratio (Fulvio et al. 2014). As dehydrogenation requires less energy than dissociation of the $\mathrm{C} \equiv \mathrm{C}$ triple bond (for which the broadband at $160 \mathrm{~nm}$ does not provide enough energy), dehydrogenation will be the dominant pathway. This is confirmed by our experimental results for detecting $\mathrm{C}_{2}$ (and not $\mathrm{CH}$ ) when $\mathrm{C}_{2} \mathrm{H}_{2}$ is embedded in a noble-gas matrix. This process is also expected to take place when irradiating pure $\mathrm{C}_{2} \mathrm{H}_{2}$. Owing to the high reactivity of the $\mathrm{C}_{2}$ and $\mathrm{C}_{2} \mathrm{H}$ radicals, they are readily converted to polyynes, resulting in steady-state column densities that are too low to be observable. The low barrier for polymerization becomes apparent when warming up the ice. During ice warmup, the resulting increase in mobility further enhances the formation of longer polyynes.

When embedding $\mathrm{C}_{2} \mathrm{H}_{2}$ in a water matrix, the water acts as a source of hydrogen and oxygen in the matrix upon VUV photolysis and their availability has a profound influence on the overall photochemistry observed. It opens a competitive reaction channel to the polymerization observed in water-poor ice. Nevertheless, polymerization can still be observed, although it is less efficient. This is remarkable, given the high abundance of water in the ice. To explain this, the absorption cross section of $\mathrm{H}_{2} \mathrm{O}$ and $\mathrm{C}_{2} \mathrm{H}_{2}$ at 122 and at $160 \mathrm{~nm}$ are compared (Mason et al. 2006; Wu et al. 2001). At both wavelengths, the absorption cross section of $\mathrm{C}_{2} \mathrm{H}_{2}$ is about one order of magnitude larger than the absorption cross section of water. As a consequence, for these settings the dissociation efficiency of $\mathrm{C}_{2} \mathrm{H}_{2}$ will be higher than for $\mathrm{H}_{2} \mathrm{O}$, explaining the preference for $\mathrm{C}_{2} \mathrm{H}_{2}$ polymerization over reaction with water-related photoproducts. However, the polymerization is still limited by the availability of $\mathrm{C}_{2} \mathrm{H}_{2}$ or related radicals present inside the matrix and with increasing fluence, water-related photochemistry takes over.

The observation of $\mathrm{CO}$ and $\mathrm{CO}_{2}$ is evidence of the destruction of the $\mathrm{C} \equiv \mathrm{C}$ triple bond although the reaction pathway is not a priori clear. The difference in photoproducts between a waterpoor environment and a water-rich environment may hint at possible pathways. In a water-poor environment, the $\mathrm{C}_{2} \mathrm{O}$ radical is observed, and is probably the result of a direct oxidation of $\mathrm{C}_{2}$. This radical has a significant lifetime inside the matrix, allowing spectroscopic detection, since the abundance of oxygen and other potential reactants is low. It can be expected that a similar process takes place in an oxygen-rich environment, but owing to the high abundance of oxygen, the $\mathrm{C}_{2} \mathrm{O}$ is oxidized further, resulting in the formation of two $\mathrm{CO}$ molecules and preventing the detection of $\mathrm{C}_{2} \mathrm{O}$.

When irradiating pure $\mathrm{C}_{2} \mathrm{H}_{2}$, small quantities of vinylacetylene $\left(\mathrm{C}_{4} \mathrm{H}_{4}\right)$ are observed. The exact reaction pathway for the formation of vinylacetylene is not clear because no intermediates (e.g. vinyl, $-\mathrm{CH}=\mathrm{CH}_{2}$, or ethene, $\mathrm{C}_{2} \mathrm{H}_{4}$ ) are observed in the spectra. It may well be possible that (excited) $\mathrm{C}_{2} \mathrm{H}_{2}$ molecules recombine. Vinylacetylene is considered an important precursor molecule in the formation of PAHs (Parker et al. 2012). The strong transitions of benzene at 3095 or $1480 \mathrm{~cm}^{-1}$
(Marzocchi et al. 1970) are totally lacking from our spectra, proving that it is absent, and by extension, that no features showing aromatic molecules are observed. This conclusion differs from the observations of Zhou et al. (2010) on the bombardment of $\mathrm{C}_{2} \mathrm{H}_{2}$ ice with $5 \mathrm{keV}$ electrons - with a similar total energy dose as applied here - where benzene was observed. It also differs from the observations of Strazzulla et al. (2002), where $\mathrm{C}_{2} \mathrm{H}_{2}$ ice was bombarded with $15 \mathrm{keV} \mathrm{N}^{+}$ions with a comparable total energy dose, and higher alkanes could be found. This is in accordance with Muñoz Caro et al. (2014, and references therein) and illustrates the dependence of solid state chemistry on the type of energy injected into the chemical system.

\section{Astrophysical implications}

Polyyne-like molecules (e.g. polyynes, $\mathrm{C}_{n} \mathrm{H}$ ) and cyanopolyynes $\left(\mathrm{HC}_{n} \mathrm{~N}\right)$ have been observed, or were said to be present on the basis of theoretical calculations, in a variety of astrophysical environments, such as active galactic nuclei (e.g. Harada et al. 2013), carbon-rich protostellar objects (e.g. Cordiner et al. 2012, 2014; Gupta et al. 2009; Sakai et al. 2009), interstellar clouds (Duley \& Hu 2009; Cernicharo et al. 1984; Herbst \& Leung 1989), and objects in the solar system, such as comets (Cordiner et al. 2014) and Uranus (Burgdorf et al. 2006). A special mention goes to the atmosphere of Titan where the photolysis of a methane plus hydrogen mixture induces a plethora of chemical reactions that lead to the formation of polyynes (Smith et al. 1998), which are also involved in the formation of the UV haze (Hunten 2006). Diacetylene $\left(\mathrm{C}_{4} \mathrm{H}_{2}\right)$, the smallest of the polyynes, has been detected by instruments on board the Huygens probe and simulations predicted the presence of gaseous $\mathrm{C}_{6} \mathrm{H}_{2}$ and $\mathrm{C}_{8} \mathrm{H}_{2}$ (Hunten 2006).

The work presented here investigates the formation route of polyynes in grain mantles, namely UV photoprocessing of acetylene-containing ices. The results of this paper along with those obtained after ion bombardment experiments of frozen $\mathrm{C}_{2} \mathrm{H}_{2}$ (Compagnini et al. 2009) give confidence that energetic processing of ices in astrophysical environments can contribute to the budget of polyynes in the universe. It is also clear that this is only a first qualitative step towards gaining insight into this field.

Subsequent thermal processing of these ices yields formation of longer chains and potentially new carbonaceous species. Further heating expels these molecules to the gas phase as the matrix desorbs. In this way, enrichment of the gas phase with new molecules takes place. The observation of vinylacetylene in the ice potentially yields a formation pathway towards PAHs to which it is known to be a precursor. This is an interesting finding, because PAHs are ubiquitous in space, and they are generally assumed to form in the outflows of AGB stars, in accordance with the experiments of Greenberg et al. (2000) that analyze gas chromatographically residues obtained after UV photolysis of ice and ice residu. The present results hint at a (complementary) bottom-up formation mechanism..

It is very well known that the photoprocessing of ice mantles in the cold clouds of the interstellar medium plays a dominant role in determining the molecular complexity of the ices. In our experiments we have used photon fluences up to $10^{18}$ photons $\mathrm{cm}^{-2}$ corresponding to exposure times of several $10^{7}$ years, i.e., comparable to time regimes that are covered in dark interstellar clouds. (Cecci-Pestellini \& Aiello 1992; Mathis et al. 1983; Prasad \& Tarafdar 1983; Mennella et al. 2003). In our 
experiments we have used photon fluences up to $10^{18}$ photons $\mathrm{cm}^{-2}$ corresponding to an exposure time ranging up to $\sim 2 \times 10^{7}$ years, perfectly compatible with the lifetime of an interstellar dark cloud. As we observed in our experiments the formation of polyynes under similar conditions, even in $\mathrm{H}_{2} \mathrm{O}-$ dominated ice, it is possible that a certain number of polyynes are formed although it is, at present, impossible to quantify their amount.

These understandings are backed up by recent observations of polyyne-like molecules in Cha-MMS1 (Cordiner et al. 2012). Their abundances are found to be in the range of $10^{-10}$ with respect to $\mathrm{H}_{2}$, are similar to those in the envelope of the older, more luminous class-0/I protostar L1527, and are greater than in another low-luminosity, low-mass class- 0 protostellar envelope (Cordiner et al. 2012). This phenomenon has been attributed by the same authors to a combination of factors including the desorption of grain mantle species into the gas phase by e.g. warming by the protostar. It is in fact well known that an important contribution to the gas phase molecules in star forming regions is given by the sublimation of carbon chain and other complex organic molecular species present in icy mantles (Modica \& Palumbo 2010; Palumbo et al. 2008).

Besides this, we provide strong clues to how to detect them inside the ice, both in the IR and in the UV-VIS range. In the case of a VUV-irradiated $\mathrm{C}_{2} \mathrm{H}_{2}$ ice, three peaks at 209.5, 219 and $228 \mathrm{~nm}$ are expected to appear in the UV absorption spectra, while in a water-dominated environment, these peaks shift about $3 \mathrm{~nm}$ to longer wavelength. They are very distinct from the UV bump at $217.5 \mathrm{~nm}$. Many of the features in the IR spectra of polyyne photoproducts feature a strong overlap with other ice components, mainly water. Therefore, the most distinct features to search for appear at 1234 and $1243 \mathrm{~cm}^{-1}$.

\section{Conclusions}

In this paper, we hqve reported a systematic laboratory study of the VUV photochemical behaviour of $\mathrm{C}_{2} \mathrm{H}_{2}$ in interstellar ices. It comprises a combined approach of two in situ techniques: FTIR spectroscopy and UV-VIS spectroscopy. The main conclusions from the experiments are:

1. The dominating reaction pathway of $\mathrm{C}_{2} \mathrm{H}_{2}$ in the solid state is polymerization resulting in formation of polyyne-like molecules upon VUV irradiation. From the spectra, polyynes in the $\mathrm{C}_{4} \mathrm{H}_{2}-\mathrm{C}_{8} \mathrm{H}_{2}$ are observed while the formation of polyynes up to at least $\mathrm{C}_{20} \mathrm{H}_{2}$ are suggested. The low reaction barrier for polymerization is indicated by the observation of polymerization upon the warming up of an irradiated ice. Under competition with water-related photoproducts, polymerization persists and polyynes are observed in a waterdominated $\mathrm{C}_{2} \mathrm{H}_{2}$ ice. This solid state process may contribute to the observed enhanced abundances of polyynes in the gas phase.

2. The spectra provided here offer a tool to search for solid state polyynes in astronomical spectra. In the IR, absorption features at $1234 \mathrm{~cm}^{-1}$ and at $1243 \mathrm{~cm}^{-1}$ are expected to appear in absorption spectra free of interaction with waterrelated bands. In the UV-VIS, the spectra of ices containing polyynes are expected to be dominated by absorption $\mathrm{C}_{8} \mathrm{H}_{2}$ features at 227.0 and $218.0 \mathrm{~nm}$.

3. The detection of vinylacetylene in the photoirradiated ice offers a first step in the pathway towards the formation of PAHs as this molecule is considered to be one of the main precursor molecules. Aromatic features are, however, not observed in our laboratory spectra.

Acknowledgements. This research is financially supported by the Netherlands School for Astronomy, NWO-VICI, the Dutch Organisation for Science, and the European Community's 7th Framework Programme (FP7/2007-2013) under grant agreement No. 238258. S.H.C. wants to acknowledge the interesting and stimulating discussions with Dr. G. Rouillé and Dr. C. Jäger from Friedrich Schiller university, Jena. G.S. is grateful to NWO for the support during his visiting period in Leiden (Apr. 30-July 28, 2012).

\section{References}

Acquista, N., Schoen, L. J., \& Lide, D. R. Jr. 1968, J. Chem. Phys., 48, 1534 Allodi, M. A., Baragiola, R. A., Baratta, G. A., et al. 2013, Space Sci. Rev., 180, 101

Behringer, R. E. 1958, J. Chem. Phys., 29, 537

Boogert, A. C. A., Pontoppidan, K. M., Knez, C., et al. 2008, ApJ, 678, 985 Bossa, J.-B., Isokoski, K., Paardekooper, D. M., et al. 2014, A\&A, 561, A136 Bouwman, J., Ludwig, W., Awad, Z., et al. 2007, A\&A, 476, 995

Bouwman, J., Paardekooper, D. M., Cuppen, H. M., Linnartz, H., \& Allamandola, L. J. 2009, ApJ, 700, 56

Burgdorf, M., Orton, G., van Cleve, J., Meadows, V., \& Houck, J. 2006, Icarus, 184,634

Carr, J. S., \& Najita, J. R. 2008, Science, 319, 1504

Cataldo, F. 2004, Tetrahedron, 60, 4265

Cataldo, F., Strazzulla, G., \& Iglesias-Groth, S. 2008, Int. J. Astrobiol., 7, 107

Cecci-Pestellini, C., Aiello, S. 1992, MNRAS, 258, 125

Cernicharo, J. 2004, ApJ, 608, L41

Cernicharo, J., Guelin, M., \& Askne, J. 1984, A\&A, 138, 371

Chang, K. W., \& Graham, W. R. M. 1982, J. Mol. Sp., 94, 69

Chen, Y.-J., Chuang, K.-J., Muñoz Caro, G. M., et al. 2014, ApJ, 781, 15

Compagnini, G., D’Urso, L., Puglisi O., Baratta, G. A., \& Strazzulla, G. 2009. Carbon, 47, 1605

Cordiner, M. A., Charnley, S. B., Wirström, E. S., \& Smith, R. G. 2012, ApJ, 744,131

Cordiner, M. A., \& Charnley, S. B. 2014, MAPS, 49, 21

Cottin, H., Moore, M. H., \& Bénilan, Y. 2003, ApJ, 590, 874

Cuylle, S. H., Tenenbaum, E. D., Bouwman, J., Linnartz, H., \& Allamandola, L. J. 2012, MNRAS, 423, 1825

Duley, W. W., \& Hu, A. 2009, ApJ, 698, 808

Falck, M., \& Whalley, E. 1961, J. Chem. Phys., 34, 1554

Fulvio, D., Brieva, A. C., Cuylle, S. H., et al. 2014, Appl. Phys. Lett., 105, 014105

Gerakines, P. A., Schutte, W. A., Greenberg, J. M., \& van Dishoeck, E. F. 1995, A\&A, 296, 810

Graham, W. R. M., Dismuke, K. I., \& Weltner, W. 1974, J. Chem. Phys., 60, 3817

Greenberg, J. M., Gillette, J. S., Muñoz Caro, G. M., et al. 2000, ApJ, 531, 71

Grutter, M., Wyss, M., Fulara, J., \& Maier, J. P. 1998, J. Phys. Chem. A, 102, 9785

Gudipati M. S., Jacovi, R., Lignell, A., \& Couturier, I. 2011, EPSC-DPS joint meeting, 6, 644

Gupta, H., Gottlieb, C. A., McCarthy, M. C., \& Thaddeus, P. 2009, ApJ, 691, 1494

Harada, N., Thompson, T. A., \& Herbst, E. 2013, ApJ 765, 108

Herbst, E., \& Leung, C. M. 1989, ApJS, 69, 271

Hunten, D. M. 2006, Nature, 443, 669

Jacox, M. E., Milligan, D. E., Moll, N. G., \& Thompson, W. E. 1965, J. Chem. Phys., 43, 3734

Jolly, A., \& Bénilan, Y. 2008, J. Quant. Spec. Rad. Transf., 109, 963

Jones, B. M., Kaiser, R. I., \& Strazzulla, G. 2014, ApJ, 781, 85

Khlifi, M., Paillous, P., Delpech, C., et al. 1995, J. Mol. Sp., 174, 116

Kim, Y. S., \& Kaiser, R. I. 2009, ApJS, 181, 543

Kloster-Jensen, E., Haink, H.-J., \& Heinz, C. 1974, Helvetica Chim. Acta, 57, 1731

Knez, C., Moore, M. H., Ferrante, R. F., \& Hudson, R. L. 2012, ApJ, 748, 95

Lacy, J. H., Evans, N. J., Achtermann, J. M., et al. 1989, ApJ, 342, L43

Lahuis, F., \& van Dishoeck, E. F. 2000, A\&A, 355, 699

Lara, L. M., Lellouch, E., Lpez-Moreno, J. J., \& Rodrigo, R. 1996, J. Geophys. Res., 101, 23261

Loison, J. C., Wakelam, V., Hickson, K. M., Bergeat, A., \& Mereau, R. 2014, MNRAS, 437, 930

Marzocchi, M. P., Bonadeo, H., \& Taddei, G. 1970, J. Chem. Phys., 53, 867

Mason, N. J., Dawes, A., Holtom, P. D., et al. 2006, Faraday Discuss., 133, 311

Mathis, J. S., Mezger, P. G., \& Panagia, N. 1983, A\&A, 128, 212 
S. H. Cuylle et al.: Vacuum ultraviolet photochemistry of solid acetylene: a multispectral approach

Mennella, V., Baratta, G. A., Esposito, A., Ferini, G., \& Pendleton, Y. J. 2003, ApJ, 587, 727

Milligan, E., Jacox, M. E., \& Abouaf-Marguin, L. 1967, J. Chem. Phys., 46, 4562

Modica, P., \& Palumbo, M. E. 2010, A\&A, 519, A22

Mumma, M. J., DiSanti, M. A., Dello Russo, N., et al. 2003, Adv. Sp. Res., 31, 2563

Muñoz Caro, G. M., Dartois, E., Boduch, P., et al. 2014, A\&A, 566, A93

Öberg, K. I., Garrod, R. T., van Dishoeck, E. F., \& Linnartz, H. 2009, A\&A, 504, 891

Okabe, H. 1975, J. Chem. Phys., 62, 2782

Okabe, H. 1978, Photochemistry of Small Molecules (New York: WileyInterscience)

Palumbo, M. E., Leto, P., Siringo, C., \& Trigilio, C. 2008, ApJ, 685, 1033

Parker, D. S. N., Zhang, F., Kim, Y. S., et al. 2012, PNAS, 109, 53

Pellerin, S., Cormier, J. M., Richard, F., Musiol, K., \& Chapelle, J. 1996, J. Phys. D, 29, 726
Prasad, S. S., \& Tarafdar, S. P. 1983, ApJ, 267, 603

Romanescu, C., Marschall, J., Kim, D., Khatiwada, A., \& Kalogerakis, K. S. 2009, Icarus, 205, 695

Sakai, N., Sakai, T., Hirota, T., Burton, M., \& Yamamoto, S. 2009, ApJ, 697, 769 Shindo, Fr., Bénilan, Y., Chaquin, P., et al. 2001, J. Mol. Sp., 210, 191

Shindo, F., Bénilan, Y., Guillemin, J.-C., et al. 2003, Planet. Space Sci., 51, 9 Smith, N. S., Gazeau, M. C., Khelifi, A., \& Raulin, F. 1998, Planet. Space Sci., 47,3

Sonnentrucker, P., González-Alfonso, E., \& Neufeld, D. A. 2007, ApJ, 671, L37 Strazzulla, G., Baratta, G. A., Domingo, M., \& Satorre, M. A. 2002, Nucl. Instr. Meth. Phys. Res. Sect. B, 191, 714

Watanabe, N., \& Kouchi, A. 2002, ApJ, 567, 651

Wu, C. Y. R., Chen, F. Z., \& Judge, D. L. 2001, J. Geophys. Res., 106, 7629

Wu, C. Y. R., Judge, D. L., Cheng, B. M., et al. 2002, Icarus, 156, 456

Wu, Y. J., \& Cheng, B. M. 2008, Chem. Phys. Lett., 461, 53

Zhou, L. Kaiser, R. I., \& Tokunaga, A. T. 2009, planss, 57, 830

Zhou, L., Zheng, W., Kaiser, R. I., et al. 2010, ApJ, 718, 1243 